\title{
El blog y wiki como herramienta docente para el trabajo colaborativo, el aprendizaje autónomo, activo y reflexivo.
}

The blog and wiki as a tool for collaborative work and active learning, autonomous and reflective

Gloria Patricia Perea González Benemérita Universidad Autónoma de Puebla Facultad de Estomatología pattypere@hotmail.com

Blanca Estrada Esquivel Benemérita Universidad Autónoma de Puebla, facultad de estomatología esstradabuap@gmail.com

Margarita Campos Méndez Benemérita Universidad Autónoma de Puebla, facultad de medicina army_campos@hotmail.com

\section{Resumen}

Mantener a los estudiantes Universitarios en el salón de clase de forma estática, escuchando la voz sonora de la misma persona durante una hora, cada día de la semana durante un cuatrimestre, es una rutina que cansa además de ser poco motivante, es por ello que como docentes, debemos hacer uso de la tecnología e innovación como apoyo en la docencia, por lo que el uso del blog y wiki permiten y apoyan en el trabajo colaborativo intra y extra muro, para el desarrollo del aprendizaje activo, autónomo y reflexivo que las nuevas generaciones deben llevar a cabo y con ello cumplir con el protagonismo y parámetros establecidos para que los estudiantes desarrollen y adquieran las competencias necesarias que propicien el aprendizaje significativo. 
Por lo descrito anteriormente, nuestro objetivo es implementar el uso de la tecnología específicamente el blog y wiki como apoyo en la docencia, así como demostrar los escenarios que permiten transformar el entorno tradicional del salón de clases, por el aprendizaje colaborativo en el ámbito educativo, y las posibilidades en mejora de la calidad, la comunicación, el desempeño y la participación de los estudiantes.

El uso del blog y wiki presenta ventajas para los estudiantes ya que accede al intercambio de ideas, trabajo colaborativo como grupo o subgrupos con fácil manejo y participación que permite la comunicación, compartir conocimientos, creación de nuevos contenidos multimedia e interacción social de los participantes. La siguiente propuesta se basa en el trabajo desarrollado durante el período agosto-noviembre de 2012 con alumnos de tercer cuatrimestre de licenciatura en Estomatología de la Benemérita Universidad Autónoma de Puebla y que cuentan con las herramientas teóricas de las TIC's para su práctica escolar y vida cotidiana.

Palabras Clave: blog, wiki, herramienta docente, aprendizaje autónomo.

\section{Abstract}

Keeping College students in the classroom statically, listening to the sonorous voice of the same person for an hour each day of the week for a semester, is a routine that besides being tired little motivating, which is why as teachers, we must use technology and innovation to support the teaching, so that the use of blog and wiki enable and support collaborative work inside and outside the wall, for the development of active learning, autonomous and reflective that new generations must carry out and thus fulfill the role and parameters established for students to develop and acquire skills that foster meaningful learning. As described above, our goal is to implement the use of technology specifically to support blog and wiki in teaching and demonstrate scenarios for transforming the traditional environment of the classroom for collaborative learning in education, and the possibilities for quality improvement, communication, performance and participation of students. The use of blog and wiki has advantages for students as it accesses the exchange of ideas, collaborative work as a group or subgroups with easy operation and participation that enables communication, knowledge sharing, creation 
of new multimedia and social interaction of the participants. The following proposal is based on work carried out during the period August to November 2012 with students in the third semester of Bachelor of Stomatology of the Autonomous University of Puebla, which have the theoretical tools of ICT for school practice and everyday life.

Key words: blog, wiki, teaching tool, autonomous learning.

Fecha recepción: septiembre 2012

Fecha aceptación: octubre 2012

\section{Introducción}

Conforme la tecnología de la información y la comunicación (TIC) ha ido avanzando, frecuentemente el sistema educativo va incorporando a la par a los docentes, con la finalidad de crear un perfil actualizado y pertinente acorde a los requisitos que la sociedad exige.

Para algunos docentes estos cambios les generan estrés, pero al incorporarse, notan las diferencias puntuales entre el enfoque tradicional y el digital o con el uso de las TIC, concibiendo la necesidad de incorporarlas para su desarrollo docente.

\begin{tabular}{|c|c|}
\hline ENSEÑANZA TRADICIONAL & USO DE LAS TIC \\
\hline ? El docente se coloca a un lado o & ? El docente se coloca a un lado de \\
atrás del escritorio lo que marca & los estudiantes los cuales se sientan \\
distancia docente-estudiante. Los & en semicírculos o círculos según la \\
estudiantes se sientan en hileras. & actividad a realizar, conformados por \\
? El espacio o aula normalmente se & equipos que ellos conforman. \\
mantiene con la puerta cerrada. & ? El espacio puede estar con la \\
? El equipo de salón de clase son & puerta abierta, se mantiene control \\
mesas y sillas; pupitres, pizarrón que & para entrar y salir si el estudiante así \\
\hline
\end{tabular}


domina el docente, y todo se presenta estático, lo prefiere.

? El equipo del espacio físico tiene dimensión virtual y social, lo que le permite buscar, analizar y compartir el conocimiento más allá de las paredes del aula, se cuenta con internet, computadora y cañón

Por lo tanto, la enseñanza tradicional ha sido transformada inevitablemente por la inclusión del mundo de la tecnología. En la enseñanza actual el uso de las TIC's vino a transformar la relación con los estudiantes, existe una interacción, generando espacios de intervención, y trabajo colaborativo en el aula. Esa comunicación personal y unilateral fue reemplazada por el proceso bilateral en la cual el docente además de transmitir sus conocimientos, recibe ideas y aprendizajes de los estudiantes.

En el uso de las TIC's como el blog, web blog o bitácora es un ejemplo de experiencia de aprendizaje profundo, sirve como un soporte personal, se distinguen de otros sitios porque el sistema publica los contenidos en orden cronológico, aunque es editable, el contenido de alguna manera es estático. La lectura es de manera continua. El autor de un blog publica artículos o noticias llamadas comúnmente entradas (post) que pueden contener texto, imágenes, video s e hipervínculos. Se puede individualizar a un artículo, contiene enlaces, comentarios, avisos, reflexiones.

Un blog es una página web de fácil actualización que se caracteriza por permitir a sus autores, editores o administradores (también llamados blogers) publicar contenidos (textos, imágenes y otros archivos) en unos cuantos pasos1.

Los blogs educativos son un espacio virtual de encuentro con nuestros estudiantes, donde pueden leer, escribir, compartir producciones realizadas por los mismos alumnos con o sin la ayuda el docente. Llegar a estos productos finales involucra la elaboración previa del docente en busca de una oportunidad de los temas que se ven en clases, actividades a desarrollar y concreción de alguna tarea o proyecto. Las tareas que los estudiantes realizan son significativas, tienen un valor propio ya que el estudiante plasma su creatividad impulsado por la motivación que las TIC's les 
provocan. Es un ejemplo de experiencia de aprendizaje profundo. Permite que los estudiantes emitan su pensamiento u opinión además de que reciben aportaciones y comentarios del docente sobre actividades a realizar, tareas, evaluaciones etc.

Otra herramienta que se puede manejar como complemento del blog es la wiki que es una herramienta de reflexión basada en proyectos que permiten la colaboración entre estudiantes y docente.

El término 'wiki wiki' es de origen hawaiano y significa "rápido" (de manera más breve se le denomina simplemente "wiki"). En términos tecnológicos, un wiki es un "software para la creación de contenido de forma colaborativa2

El impacto de un wiki es la articulación de poder aprender juntos, planificar las actividades y redactar proyectos, tareas o trabajos. Permite el intercambio de conocimientos además de planificar las actividades a realizar. Un wiki educativo es un sitio web cuyas páginas pueden ser editadas por múltiples voluntarios a través del navegador web. Los usuarios pueden crear, modificar o borrar un mismo texto que comparten. Los textos tienen títulos únicos. Si se escribe el título de una página wiki esta palabra se convierte en un enlace o link.

Tanto el blog como el wiki tienen ventajas e inconvenientes en el ámbito educativo que todo usuario debe conocer, cuando es para uso educativo facilita la labor docente.

\begin{tabular}{|c|c|c|}
\hline Blogs & \multirow{6}{*}{ Ventajas } & Wikis \\
\hline & & Inter/Intra conectividad \\
\hline Divulgación & & Interactividad \\
\hline Flexibilidad & & Flexibilidad \\
\hline Aula interactiva & & Versatilidad \\
\hline $\begin{array}{l}\text { Diversidad de recursos } \\
\text { en el aula. Integrar los }\end{array}$ & & $\begin{array}{l}\text { Seguimiento del aprendizaje } \\
\text { y evaluación del docente }\end{array}$ \\
\hline
\end{tabular}




\begin{tabular}{|c|c|c|}
\hline $\begin{array}{l}\text { temas de las } \\
\text { asignaturas, orientación } \\
\text { del trabajo en red, } \\
\text { accesibilidad y conexión } \\
\text { entre el trabajo en clase } \\
\text { y extramuro. }\end{array}$ & & $\begin{array}{l}\text { Aprendizaje cooperativo, } \\
\text { colaborativo, desarrollo de } \\
\text { habilidades, redacción, } \\
\text { comunicación, ortografía }\end{array}$ \\
\hline $\begin{array}{l}\text { Si se deja abierto los } \\
\text { estudiantes desarrollen, } \\
\text { mediante trabajo } \\
\text { cooperativo, habilidades } \\
\text { en: redacción, } \\
\text { comunicación gráfica, } \\
\text { alfabetismo en medios y } \\
\text { competencias. }\end{array}$ & & $\begin{array}{l}\text { Favorece el aprendizaje } \\
\text { individual e investigación, } \\
\text { Permitir conocer la opinión } \\
\text { de la audiencia por } \\
\text { comentarios que se dejen, } \\
\text { generando una } \\
\text { retroalimentación. }\end{array}$ \\
\hline $\begin{array}{l}\text { Si se deja abierto los } \\
\text { estudiantes } \\
\text { acompañar } \\
\text { información con recursos } \\
\text { multimedia } \\
\text { sonido, como } \\
\text { hipertexto, videos, } \\
\text { animaciones, } \\
\text { fotografías e imágenes }\end{array}$ & & $\begin{array}{l}\text { Los estudiantes y docentes } \\
\text { pueden acompañar la } \\
\text { información con recursos } \\
\text { multimedia como sonido, } \\
\text { videos, hipertexto, } \\
\text { hipervínculos, animaciones, } \\
\text { texto, fotografías e imágenes }\end{array}$ \\
\hline $\begin{array}{l}\text { No se puede seguir el } \\
\text { aprendizaje }\end{array}$ & Inconvenientes & $\begin{array}{llr}\text { Bandidaje cuando su } & \text { abierta } \\
\text { estructura es } & \\
\text { cualquier usuario }\end{array}$ \\
\hline Gran dedicación por & & Por la estructura y creación \\
\hline
\end{tabular}




\begin{tabular}{|l|l|l|}
\begin{tabular}{|l|l|} 
parte del docente para el \\
diseño, coordinar \\
trabajos y evaluar.
\end{tabular} & $\begin{array}{l}\text { del usuario, su credibilidad } \\
\text { es cuestionable }\end{array}$ \\
\hline $\begin{array}{l}\text { Limitaciones de acceso } \\
\text { que imponen las } \\
\text { circunstancias externas: } \\
\text { situaciones rocio } \\
\text { económicas de los } \\
\text { alumnos, dotaciones de } \\
\text { recursos de los centros y } \\
\text { formación del docente. }\end{array}$ & $\begin{array}{l}\text { Limitaciones de acceso que } \\
\text { imponen las circunstancias } \\
\text { externas: situaciones socio } \\
\text { económicas de los alumnos, } \\
\text { dotaciones de recursos de los } \\
\text { centros y perfil del docente }\end{array}$ \\
\hline
\end{tabular}

Los blogs y wikis tienen distintas características que los hacen diferentes y por ello su uso depende de las necesidades del usuario.

Se permite hacer copias digitales o impresas de todo o parte del blog o wiki para uso personal o académico. Cuando la wiki es usada por el docente, le permite verificar los accesos de los estudiantes y el aporte a cada tarea o trabajo. Al subir la información cada líder de equipo, el docente puede seleccionar la que tenga mejor contenido así como hacer observaciones a cada actividad.

\section{Contenido}

Las TIC's constituyen un campo ideal que genera cambios en el ámbito educativo ya que es significativa, por cuanto configuran un nuevo paradigma que impone cambios en la concepción del proceso educativo, de la tecnología, de las estrategias de aprendizaje - enseñanza, el papel que desempeña cada integrante involucrado, la concepción del aprendizaje como proceso complejo y mediado y la actualización docente.

En el marco de las innovaciones, las instancias universitarias requieren incorporar a su metodología avances tecnológicos por lo que las bondades de las TIC's dan lugar a iniciativas y ánimos para mejorar la enseñanza universitaria. El propósito de este 
trabajo, es compartir las experiencias y aprovechar la información, para propiciar la formación y actualización del docente, en virtud de la factibilidad y rapidez para obtener desde su casa o sitio de trabajo, información actualizada de distintos ámbitos, explorar las posibilidades metodológicas de las TIC's en la enseñanza universitaria como una alternativa que reconoce la práctica pedagógica en el campo de conocimiento, mediante el empleo de un prototipo que se apoya en las potencialidades del Internet (blogs y wikis), cuyas bondades pueden ser aprovechadas lo que permite ampliar la cobertura de los docentes en servicio, tanto dentro como fuera del aula y a su vez que los estudiantes se apoyen de los recursos antes mencionados.

Después de conocer las ventajas, inconvenientes y características de los blogs y wikis, se comparten las experiencias como apoyo docente y para que los estudiantes participen.

Se diseñó un blog por parte del docente lo que permitió que los estudiantes conocieran y participaran al $100 \%$ en las diferentes actividades. Se contempló en el blog el encuadre lo que ayudó a que al momento de la presentación los estudiantes preguntaran y participaran sobre el contenido temático, el que está conformado por unidades, respecto a los parámetros para la evaluación diagnóstica, formativa y sumativa también los estudiantes propusieron ideas y se adjuntaron rúbricas, otro de los contenidos fue la bibliografía básica y complementaria. Se abrió una pestaña específica para que cada subgrupo expresara las opiniones o comentarios del equipo antes, durante y al final de cada tema, la información se subirá exclusivamente por parte del líder del equipo.

Con este espacio, el docente conocerá, analizará y observará la participación de cada estudiante y con ello evitar que unos trabajen y otros no en las actividades intra y extramuro. Al estar al tanto de lo sucedido en el aula o fuera de ella, tendrá la oportunidad de ir verificando y corrigiendo si fueran necesarias las tareas, contenidos del programa entre otros y además que la evaluación sea justa.

\section{Metodología}


La investigación es de corte longitudinal, comparativa y observacional.

Universo: alumnos de la Benemérita Universidad Autónoma de Puebla de la facultad de Estomatología.

Muestra: alumnos de tercer cuatrimestre que cursan la materia de estomatología integral I. Período agosto-diciembre 2011. Características del grupo: edades entre 20 y 21 años. El 6\% trabaja y el $94 \%$ indica que se dedica al estudio. El $89 \%$ ya cursó la materia desarrollo de habilidades en la tecnología de la información y comunicación.

Muestra: alumnos de tercer cuatrimestre que cursan la materia de estomatología integral I. Período agosto-diciembre 2012. Características del grupo: de los participantes son 11 hombres y 24 mujeres, edades entre 20 y 21 años. El $1.7 \%$ son casados, $4.3 \%$ trabaja y el $94 \%$ indica que se dedica al estudio. El $90 \%$ ya cursó la materia desarrollo de habilidades en la tecnología de la información y comunicación.

En comparación con los estudiantes del período agosto-diciembre 2011 , donde no se había hecho uso de las TIC's (blog y wiki), la participación de los estudiantes en clase fue solo durante sus presentaciones sin distinción alguna con la desventaja que los estudiantes no están formados para comunicar quién verdaderamente había colaborado con la actividad.

Para poner en función el programa, se realizó una evaluación diagnóstica sobre el conocimiento sobre el uso de las TIC's, blog y wiki. Se explica durante el encuadre la manera de cómo se va a trabajar con el blog y wiki.

Se dan roles que deben jugar cada integrante del equipo

Subdividir el grupo en equipos (máximo 5 integrantes) nominando al líder de cada equipo quien será el encargado de subir la información ya terminada y se autonombran.

Se recuerda que todos los estudiantes tienen acceso a ver el contenido del blog.

El docente, envía invitación a cada jefe de equipo para entrar y participar en el blog

De los cinco subgrupos formados, todos participan en las diferentes actividades. 
Para que el docente mantenga un control del trabajo, realiza un portafolio de evidencias y así evalúe el comportamiento y participación de cada estudiante, por lo que cada sub grupo abre un wiki que permite observar quien participa, contenido, aporte y número de veces que participo.

Por este medio se presenta el grado de desarrollo para el uso de los blogs educativos y wikis, a través de su aplicación en el aula para participar en el salón de clase así como para la realización de tareas grupales colaborativas.

Una vez revisado el contenido del blog, los estudiantes realizan la primera actividad señalada en el blog por lo que abren su wiki, se autonombran y se dan a la tarea de participar hasta concluir la tarea asignada. Se considera para la evaluación: contenido, desarrollo del tema, ejemplos aplicables a casos clínicos, preguntas, hipervínculos, conclusión y bibliografía para posteriormente realizar la presentación del trabajo en equipo y se hará por sorteo.

Para el desarrollo de cada tema que será presentado se dan de tres a cinco días para su elaboración y revisión. Durante esos días el docente aborda otros temas y refuerza sobre los ya vistos.

\section{Resultados}

Después de hacer un diagnóstico previo a la experiencia para posteriormente realizar el análisis comparativo entre la enseñanza tradicional y la enseñanza con apoyo del uso de las TIC's (blog, wiki, power point, videos, blogs comunes etc.) los resultados son los siguientes:

Se exponen los resultados obtenidos a través del diagnóstico previo a la experiencia, la apreciación general del proceso instruccional desde la perspectiva del participante y la valoración del paradigma utilizado (blog y wiki)

Resultados del diagnóstico

El $100 \%$ utiliza algún programa de computación. La mitad de los alumnos han participado en alguna experiencia de aprendizaje como usuario en la que emplea la computadora. 
Respecto a los resultados sobre el uso del blog, wiki, apoyo de aprendizaje se obtuvo lo siguiente:

Los estudiantes llegaron a la conclusión que tanto el blog (85\%) como el wiki (92\%) figuraron como una novedad en beneficio del proceso aprendizaje (95\%).

Consideraron que la organización de su trabajo fue mejor (87\%) con ciertas comodidades para su desarrollo (85\%). Algunos estudiantes (35\%) presentaron ciertas dificultades para encontrar información confiable, al haber interacción dificultosa (63\%) entre los compañeros del grupo, en ocasiones no se comunicaron de modo pertinente. Por lo que sugieren la necesidad de contar con todos los correos electrónicos para que se haga una comunicación más viable y adecuada.

Respecto a los resultados en la evaluación sumativa son los siguientes:

El aprendizaje significativo para los estudiantes en 2012 corresponde al 98\%, se dio al $100 \%$ del trabajo colaborativo, lo que permitió la participación activa y reflexiva en un $93 \%$, por consiguiente los estudiantes desarrollaron sus habilidades en un $95 \%$ lo que al unir los rubros anteriores permitió que se generara aprendizaje significativo.

\section{Conclusión}

Es necesario concentrarnos en la significación del concepto digital en el aula como apoyo en la docencia. Como docentes, debemos poseer el conocimiento necesario sobre el uso educativo de los recursos que ofrecen las TIC's

Considerar que el solo hecho de poseer computadoras y conexión es suficiente, la clave está en la preparación del docente. Los proyectos institucionales deben incluir el uso de nuevas tecnologías para lograr mejores resultados en los procesos de enseñanza y aprendizaje

La totalidad de los alumnos registran que para el aprendizaje autónomo, activo y reflexivo se debe emplear recursos como la computadora, ya que favorece el estudio independiente. 
Aunque un buen porcentaje de los participantes, destacaron aspectos satisfactorios con relación a la experiencia. Su disposición para intervenir en línea es altamente positiva, lo cual indica que se satisfacen las expectativas de los alumnos con respecto al diseño instruccional y su alto grado de acuerdo sobre la facilidad del uso del blog y wiki así como su adecuada presentación, ponen de manifiesto el éxito de esta experiencia.

Aun cuando los resultados de la experiencia desarrollada ponen en evidencia que fue positiva en términos generales y que conviene mejorarla atendiendo a las recomendaciones formuladas por los usuarios, se tiene la convicción, tal como lo plantea Ávila Dorado3 (Sep 2009) que las TICs son instrumentos que presentan contenidos para alcanzar un fin.

La incorporación de las tecnologías a la educación son eficaces si son concebidas y aplicadas con el propósito expreso de fomentar el aprendizaje autónomo, activo y reflexivo y el desarrollo del trabajo colaborativo

\section{Bibliografía}

Anónimo (19 de Noviembre de 2012). ¿Qué es un Weblog? [Mensaje en un blog]. Recuperado de http://www.minid.net/que-es-un-weblog/

Avila Dorado C (1 de Octubre de 2009). Uso educativo de los blogs. Características de Blogger. [Mensaje en un blog]. Recuperado de http://www.eduteka.org/BlogsWordpress.php

Àvila, C. (2010). Uso educativo de los wikis. Características de Wikispaces. Recuperado de http://www.eduteka.org/Wikispaces.php 